\title{
Hexabromocyclododecane in municipal wastewater treatment plant: Occurrence, fate and potential environmental risks
}

\author{
Joy Ann De Guzman ${ }^{1, a}$ \\ ${ }^{1}$ Institute of Environment for Sustainable Development, College of Environmental Science and \\ Engineering, Tongji University, Shanghai 200092, China
}

ajoyanndeguzman@tongji.edu.cn

\begin{abstract}
Keywords: HBCD; WWTP; environmental impact; risk assessment.
Abstract. Wastewater and sewage sludge samples were collected from a conventional wastewater treatment plant (WWTP) in Shanghai, and the concentrations of a frequently detected brominated flame retardant (BFR), namely hexabromocyclododecane (HBCD), were determined. In wastewater samples, HBCD was detected in concentrations ranging from 1.2 to $1.7 \mathrm{ng} / \mathrm{L}$, and in sewage sludge, HBCD level was detected to be $2.2 \mathrm{ng} / \mathrm{g}$ dry weight, which was in the low end of HBCD levels reported worldwide. The daily releasing loading of $\mathrm{HBCD}$ via final effluent and sewage sludge were calculated to be 73 and $70 \mathrm{mg}$, respectively, suggesting that WWTP could be a potential pollution source of HBCD in municipal environment.
\end{abstract}

\section{Introduction}

As a group of brominated flame retardant (BFR), hexabromocyclododecane (HBCD) have been widely used in a large variety of thermal insulation materials and household textile products $[1,2]$. The global demand for HBCD reached 16,700 tons in 2001, not as many as the other two BFRs, which are polybrominated diphenyl ethers (PBDEs) and tetrabromobisphenol A (TBBPA) [3]. There are three major diastereoisomers in commercial HBCD products, including $\alpha$-HBCD $(10-13 \%), \beta-H B C D$ $(1-12 \%)$, and $\gamma$-HBCD (75-86\%) [4, 5]. Since HBCD have been heavily used in high impact polystyrene foams which are applied as thermal insulation materials in modern buildings and it is not chemically bound with products, HBCD may be released to indoor environment and further transport to other municipal environmental compartments. HBCD have been widely detected in various environmental compartments from the world, even in remote areas with no identified pollution sources surrounding, suggesting the long range transport potential of HBCD [6, 7]. Meanwhile, HBCD was found to accumulate and magnify along with food chain, which could pose a direct threat to human health $[8,9]$. Although the acute toxicity of HBCD appear to be quite low, some adverse effects were observed for neurodevelopment and thyroid hormones in lab animal toxicity tests $[10,11]$. Due to the persistency of HBCD in the environment, as long as its potential to accumulate via food chain, it has been included in the list of persistent organic pollutants (POPs) under the Stockholm convention [12]. Although the production and application of HBCD have ceased gradually in the world since 2013, there are products containing it on the market, and more importantly, the emission of HBCD from household environment is a rather slow process.

As mentioned above, various house products currently in use are likely to contain large amounts of HBCD. And after being released from these products, HBCD may be adsorbed onto indoor dusts, due to its strong hydrophobicity. Then along with municipal waste collection system and dry or wet deposition, HBCD is likely to enriched in wastewater treatment plants (WWTPs). Since no specific removal technologies targeting organic pollutants like HBCD were applied in WWTPs at present, HBCD entering WWTPs may not be largely eliminated during wastewater treatment processes, which will continue to transport in municipal environment via final effluent and sewage sludge. In this study, the concentrations of HBCD were determined in several major wastewater treatment stages from a conventional WWTP located in Shanghai, and the potential releasing risks of HBCD from WWTPs were also assessed in this area. 


\section{Methods}

Wastewater and dewatered sludge samples were collected from several wastewater treatment stages, including primary settling tank, aeration tank, secondary settling tank, anaerobic-anoxic-oxic tank, UV disinfection tank, and sludge concentration tank. After transported to the lab, wastewater samples were kept at $0{ }^{\circ} \mathrm{C}$, and sewage sludge samples were kept at $-20{ }^{\circ} \mathrm{C}$ until analysis. Firstly, wastewater samples were filtered with glass fiber filters with diameter of $0.75 \mu \mathrm{m}$, and then further divided into dissolved phase and particulate phase. Soxhlet extraction were used to extract HBCD from wastewater and sewage sludge samples, and dichloromethane as the solution was selected. After extraction, several purification procedures were applied to avoid any possible interference of impurities, including purification with concentrated sulfuric acid, sulfur removal with copper sheets, and purification with gel permeation column. Finally, extraction solutions were concentrate to $100 \mu \mathrm{L}$ and hexane as the stock solution was selected. HPLC-MS/MS was selected to perform instrumental analysis for HBCD in both of the wastewater and sewage sludge samples.

\section{Results}

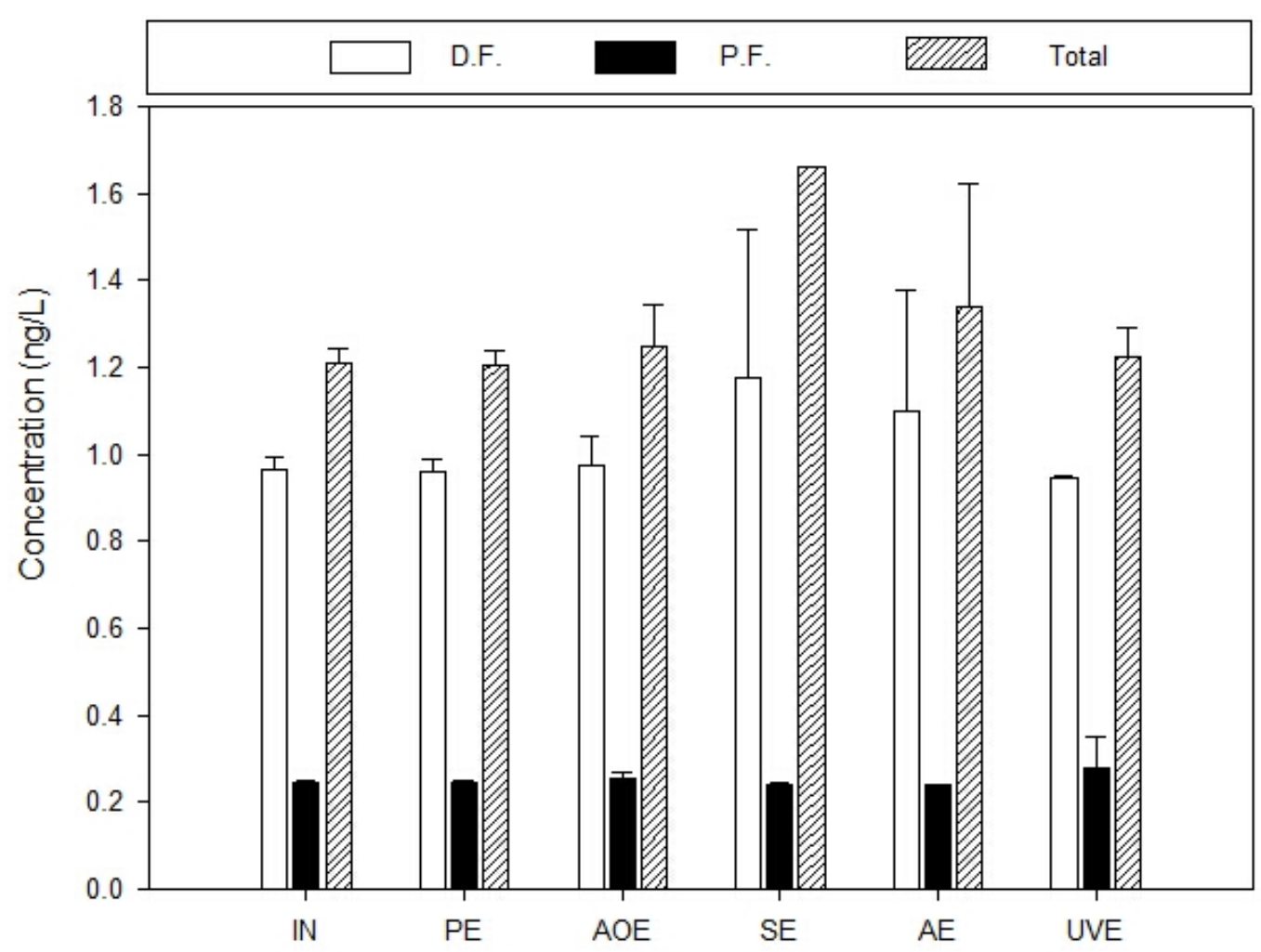

Figure 1. Concentrations of HBCD in wastewater samples.

As shown in Figure 1., the concentrations of HBCD in the influent, effluent from primary settling tank, $\mathrm{A}^{2} / \mathrm{O}$ tank, secondary settling tank, aeration tank, and UV disinfection tank were determined to be 1.2 $\mathrm{ng} / \mathrm{L}, 1.2 \mathrm{ng} / \mathrm{L}, 1.3 \mathrm{ng} / \mathrm{L}, 1.7 \mathrm{ng} / \mathrm{L}, 1.3 \mathrm{ng} / \mathrm{L}$, and $1.2 \mathrm{ng} / \mathrm{L}$, which were clearly lower than that of PBDEs, which was consistent with the application history of these two BFRs [13, 14]. The concentrations of HBCD in the dissolved phase were slightly higher than that in the particulate phase, which might be caused by the physico-chemical properties of HBCD, such as octanol-water partition coefficients. Although categorized as hydrophobic pollutants, the water solubility of HBCD was higher than that of PBDEs, and reached $65.6 \mu \mathrm{g} / \mathrm{L}$ at $20^{\circ} \mathrm{C}$ [15]. As a result, HBCD was not largely removed during primary and secondary settling tank. Similarly, no significant elimination was observed during anaerobic digestion and UV disinfection, resulting in consistent HBCD concentrations during wastewater treatment processes, which is conformed with pervious assumptions. 
In sewage sludge, the concentration of HBCD were determined to be $2.2 \mathrm{ng} / \mathrm{g}$ dry weight, which was comparable with that detected in sewage sludge samples from Czech Republic [16], but one to two orders of magnitude lower than that observed in similar studies from Sweden and Swiss [17, 18]. According to previous studies, Europe used to be the major application market for HBCD and over $50 \%$ of world's total HBCD production was consumed in Europe, which might explain the high levels of HBCD in sewage sludge samples from European countries.

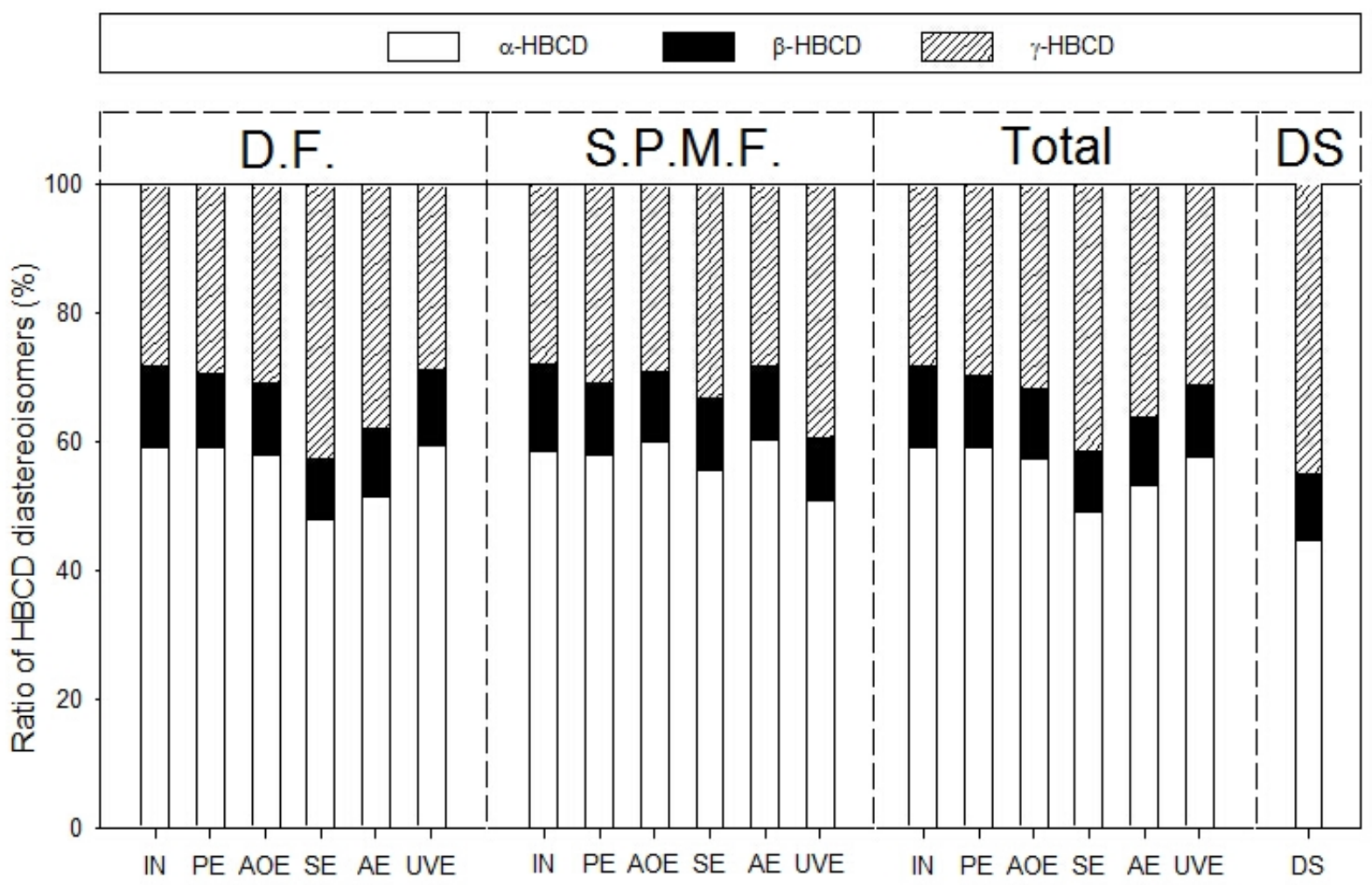

Figure 2. Diastereoisomer profiles of HBCD in wastewater and sewage sludg samples.

During wastewater treatment processes, the diastereoisomer profiles of HBCD were quite consistent, as shown in Figure 2. The fractions of $\alpha$-HBCD were detected to be $48-60 \%$ and $51-60 \%$ in the dissolved phase and particulate phase, respectively, which were all slightly higher than that of $\gamma$-HBCD. And the fractions of $\beta$-HBCD was consistently lower than $10 \%$ in all the wastewater samples. As mentioned above, $\gamma$-HBCD was found to the major diastereoisomer in commercial products. One reason might be the difference in water solubility between $\alpha$-HBCD and $\gamma$-HBCD. Among there HBCD diastereoisomers, the water solubility of $\alpha$-HBCD was detected to be the highest $(48.8 \mu \mathrm{g} / \mathrm{L})$, much higher than that of $\gamma$-HBCD $(2.1 \mu \mathrm{g} / \mathrm{L})[19,20]$. Similarly, in sewage sludge, different HBCD diastereoisomer profiles with commercial products were observed, and one possible explanation could be thermal rearrangement during the production of HBCD-containing products [21].

Based on the capacity of this WWTP and HBCD concentrations in wastewater and sewage sludge samples, it was calculated that of all the $143 \mathrm{mg}$ of HBCD entering this WWTP, $49 \%$ accumulated in sewage sludge, and 51\% was released to the receiving water bodies via final effluents. And as a result, the annual releasing load via sewage sludge in this area was calculated to be $1.5 \mathrm{~kg}$.

\section{Conclusions}

Three HBCD diastereoisomers were all detected in wastewater and sewage sludge samples from the WWTP, suggesting the wide occurrence of HBCD in this area. During wastewater treatment processes, no significant removal was observed for HBCD both in the dissolved phase and particulate phase. Unlike that in the commercial HBCD products, $\alpha$-HBCD was found to be the dominant diastereoisomer in the WWTP, which should arouse more concern, since the bioavailability of $\alpha-\mathrm{HBCD}$ was highest among three HBCD diastereoisomers. Considering the continual releasing of 
HBCD via final effluents and sewage sludge, further monitoring for the occurrence of HBCD in municipal WWTPs is quite necessary.

\section{References}

[1] Covaci, A., A.C. Gerecke, R.J. Law, et al., Hexabromocyclododecanes (HBCDs) in the environment and humans: A review. Environmental Science \& Technology, 2006. 40(12): 3679-3688. [2] de Wit, C.A., An overview of brominated flame retardants in the environment. Chemosphere, 2002. 46(5): 583-624.

[3] Birnbaum, L.S. and D.F. Staskal, Brominated flame retardants: Cause for concern? Environmental Health Perspectives, 2004. 112(1): 9-17.

[4] Budakowski, W. and G. Tomy, Congener-specific analysis of hexabromocyclododecane by high-performance liquid chromatography/electrospray tandem mass spectrometry. Rapid Communications in Mass Spectrometry, 2003. 17(13): 1399-1404.

[5] Morris, S., C.R. Allchin, B.N. Zegers, et al., Distributon and fate of HBCD and TBBPA brominated flame retardants in north sea estuaries and aquatic food webs. Environmental Science \& Technology, 2004. 38(21): 5497-5504.

[6] Hoh, E. and R.A. Hites, Brominated flame retardants in the atmosphere of the east-central United States. Environmental Science \& Technology, 2005. 39(20): 7794-7802.

[7] Remberger, M., J. Sternbeck, A. Palm, et al., The environmental occurrence of hexabromocyclododecane in Sweden. Chemosphere, 2004. 54(1): 9-21.

[8] Tomy, G.T., K. Pleskach, T. Oswald, et al., Enantioselective bioaccumulation of hexabromocyclododecane and congener-specific accumulation of brominated diphenyl ethers in an eastern Canadian Arctic marine food web. Environmental Science \& Technology, 2008. 42(10): 3634-3639.

[9] Law, K., T. Halldorson, R. Danell, et al., Bioaccumulation and trophic transfer of some brominated flame retardants in a Lake Winnipeg (Canada) food web. Environmental Toxicology and Chemistry, 2006. 25(8): 2177-2186.

[10] Palace, V.P., K. Pleskach, T. Halldorson, et al., Biotransformation enzymes and thyroid axis disruption in juvenile rainbow trout (Oncorhynchus mykiss) exposed to hexabromocyclododecane diastereoisomers. Environmental Science \& Technology, 2008. 42(6): 1967-1972.

[11] Ema, M., S. Fujii, M. Hirata-Koizumi, et al., Two-generation reproductive toxicity study of the flame retardant hexabromocyclododecane in rats. Reproductive Toxicology, 2008. 25(3): 335-351.

[12] Stockholm Convention. UN chemical experts recommend that widely used flame retardant be phased out of global production and use. 2012 2012]; Available from: http://chm.pops.int/Convention/Media/PressReleases/HBCDcontrolunderglobalchemicalstreaty/tabid /2895/Default.aspx.

[13] Law, R.J., D. Herzke, S. Harrad, et al., Levels and trends of HBCD and BDEs in the European and Asian environments, with some information for other BFRs. Chemosphere, 2008. 73(2): 223-241. [14] Alaee, M., P. Arias, A. Sjödin, et al., An overview of commercially used brominated flame retardants, their applications, their use patterns in different countries/regions and possible modes of release. Environment International, 2003. 29(6): 683-689.

[15] Marvin, C.H., G.T. Tomy, J.M. Armitage, et al., Hexabromocyclododecane: Current understanding of chemistry, environmental fate and toxicology and implications for global management. Environmental Science \& Technology, 2011. 45(20): 8613-8623.

[16] Pulkrabová, J., J. Hajšlová, J. Poustk, et al., Brominated flame retardants in river sediments and sewage sludges collected in the Czech Republic. Proceedings of the 4th International Workshop on Brominated Flame Retardants, 2007.

[17] Kupper, T., L.F. de Alencastro, R. Gatsigazi, et al., Concentrations and specific loads of brominated flame retardants in sewage sludge. Chemosphere, 2008. 71(6): 1173-1180. 
[18] de Wit, C.A., K. Nylund, U. Eriksson, et al. Brominated flame retardants in sludge from 50 Swedish sewage treatment plants: Evidence of anaerobic degradation of HBCD and TBBPA. in Proceedings of the 4th International Workshop on Brominated Flame Retardants. 2007. Amsterdam, The Netherlands: BFR 2007 organizing committee.

[19] Heeb, N.V., W.B. Schweizer, M. Kohler, et al., Structure elucidation of hexabromocyclododecanes - a class of compounds with a complex stereochemistry. Chemosphere, 2005. 61(1): 65-73.

[20] Hunziker, R.W., S. Gonsior, J.A. MacGregor, et al., Fate and effect of hexabromocyclododecane in the environment. Organohalogen Compounds, 2004. 66: 2275-2280.

[21] Peled, M., R. Scharia, and D. Sondack, Thermal rearrangement of hexabromo-cyclododecane (HBCD), in Industrial Chemistry Library, B.G. Jean-Roger Desmurs and J.G. Melvin, Editors. 1995, Elsevier. p. 92-99. 